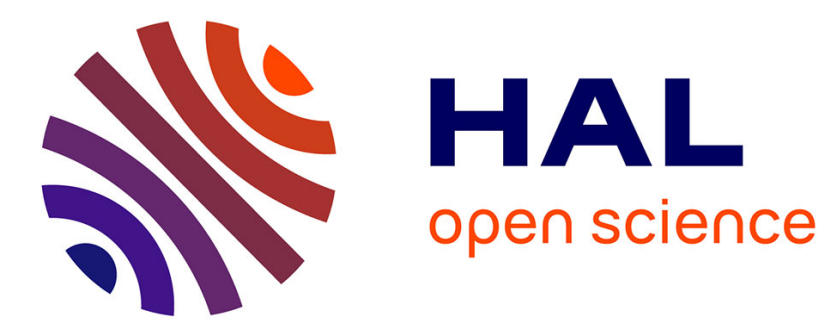

\title{
The Cloud Phase Discrimination From a Satellite
}

\author{
A.A. Kokhanovsky, O. Jourdan, J.P. Burrows
}

\section{To cite this version:}

A.A. Kokhanovsky, O. Jourdan, J.P. Burrows. The Cloud Phase Discrimination From a Satellite. IEEE Geoscience and Remote Sensing Letters, 2006, 3 (1), pp.103 - 106. 10.1109/lgrs.2005.858487. hal-01893570

\section{HAL Id: hal-01893570 \\ https://hal.science/hal-01893570}

Submitted on 3 Dec 2021

HAL is a multi-disciplinary open access archive for the deposit and dissemination of scientific research documents, whether they are published or not. The documents may come from teaching and research institutions in France or abroad, or from public or private research centers.
L'archive ouverte pluridisciplinaire HAL, est destinée au dépôt et à la diffusion de documents scientifiques de niveau recherche, publiés ou non, émanant des établissements d'enseignement et de recherche français ou étrangers, des laboratoires publics ou privés. 


\title{
The Cloud Phase Discrimination From a Satellite
}

\author{
A. A. Kokhanovsky, O. Jourdan, and J. P. Burrows
}

\begin{abstract}
A new technique to identify mixed-phase clouds but also clouds with supercooled water droplets using satellite measurements is proposed. The technique is based on measurements of the backscattered solar light at wavelengths 1.55 and $1.67 \mu \mathrm{m}$ in combination with cloud brightness temperature measurements at $12 \mu \mathrm{m}$. For the first time, the concept of the phase index-temperature correlation plot (the P-T diagram) is introduced in the cloud remote sensing. Retrievals of cloud temperature and cloud phase index are performed using data from the Advanced Along Track Scanning Radiometer (AATSR) and Scaning Imaging Absorption Spectrometer for Atmospheric Chartography (SCIAMACHY) both onboard the Envisat platform.
\end{abstract}

Index Terms-Cloud remote sensing, temperature, thermodynamic phase.

\section{INTRODUCTION}

$\mathbf{T}$ HE thermodynamic state (TS) of clouds influences precipitation, atmospheric dynamics, radiation, heat, and mass transfer. The proper partitioning of cloud phase is particularly important in precipitation processes as it directly impacts on the type of hydrometeors released (rain, snow, hail, sleet, etc.). The identification of cloud thermodynamic phase is not only critical for precipitation prediction but also to specify the accurate optical and microphysical properties of clouds. In this respect, Knap et al. [5] stated that the determination of the phase of clouds should be regarded as the first step in algorithms designed for the retrieval of cloud properties from satellite measurements. Additionally, the assessment of the TS of clouds is relevant to solve applied problems such as the icing occurring on an aircraft. As a result, the problem of the TS determination attracted a considerable amount of attention in the past (see among others, Acarreta et al. [1], Baum et al. [2], Knap et al. [5], and Turner et al. [12]). In particular, a comprehensive dataset related to the cloud TS was obtained using satellite-based infrared (IR) observations [2]. It was found that, generally, the brightness temperature difference between channels located at 8.5 and $11 \mu \mathrm{m}$ is positive for ice clouds and is negative for water clouds. However, one important shortcoming of an IR-based method to detect the cloud phase lies in the fact that the technique is not capable to deal with supercooled water or mixed-phase clouds.

We propose here to use in addition to thermal IR data, measurements at wavelengths $\lambda 1550$ and $1670 \mathrm{~nm}$. In fact, it is known that the absorption spectra of ice and water display significant differences in the spectral range $[1550 \mathrm{~nm}$, $1670 \mathrm{~nm}$ ] [5], [9]. Therefore, this specific behavior can be

Manuscript received April 21, 2005; revised July 20, 2005. This work was supported in part by the Alexander von Humboldt Foundation and in part by the German Research Foundation (DFG) under Project BU 688/8-1.

The authors are with the Institute of Environmental Physics, University of Bremen, D-28334 Bremen, Germany (e-mail: alexk@iup.physik.uni-bremen. de).

Digital Object Identifier 10.1109/LGRS.2005.858487

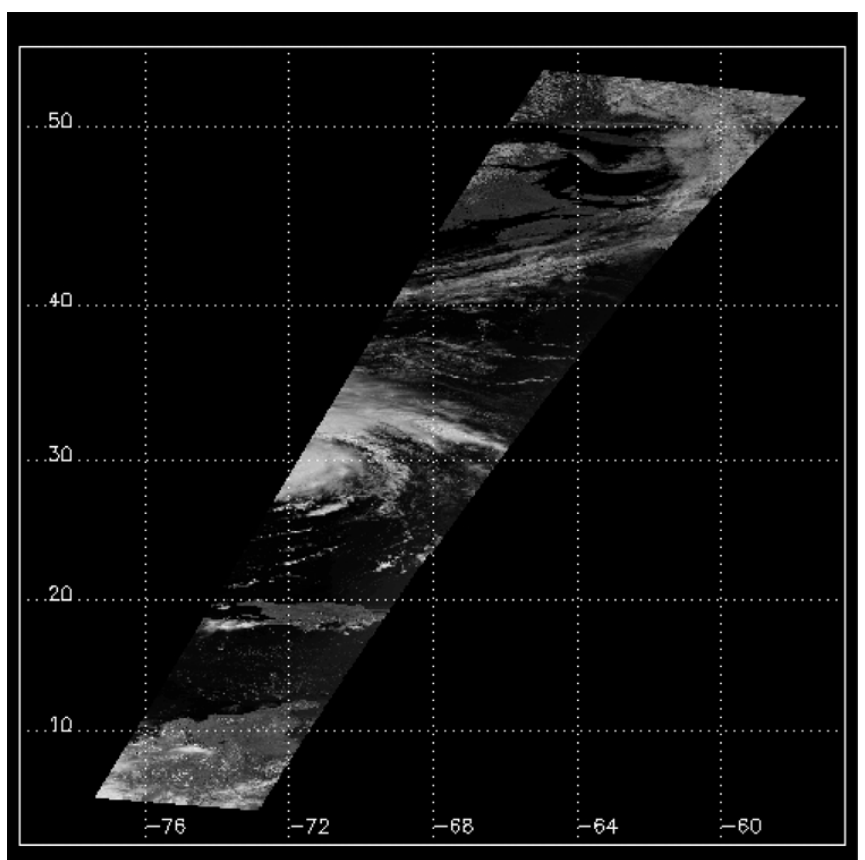

Fig. 1. Browse image of the scene studied. A sample of Hurricane Isabel (17.09.2003, 14:50UTC) captured by AATSR instrument onboard Envisat (orbit 08094) is seen in the middle of image.

used to enhance the thermodynamic phase retrievals based on thermal infrared measurements. Unfortunately, instruments capable of measuring radiances simultaneously at wavelengths $1.55,1.67,8.7$, and $11 \mu \mathrm{m}$ are not available. Consequently, simultaneous satellite measurements over the same cloud field but using different instruments installed on the same space platform were combined to infer cloud field TS. This technique enables the discrimination of warm water clouds from ice clouds, mixed-phase states, and supercooled water clouds.

Specifically, we used measurements at the wavelength $12 \mu \mathrm{m}$ from the Advanced Along Track Scanning Radiometer (AATSR) on Envisat. Measurements at 1.55 and 1.67 were obtained using Scaning Imaging Absorption Spectrometer for Atmospheric Chartography (SCIAMACHY) [3]. Further information on these instruments can be found on the following website: http://www.esa.int/envisat/instruments.html. In this study, SCIAMACHY measurements had a spatial resolution of $30 \times 60 \mathrm{~km}^{2}$, whereas AATSR data had a resolution of $1 \mathrm{~km}^{2}$. Therefore, the AATSR measurements were integrated to the size of SCIAMACHY pixel. Additionally, only SCIAMACHY pixels with cloud fractions $c$ above $99 \%$ and over an underlying ocean surface were used in this study. The values of $c$ for SCIAMACHY pixels were obtained using collocated highly spatially resolved AATSR data. The AATSR pixel has been considered as a completely cloudy one if the reflection function $R$ in the visible correspondent to this pixel exceeded 


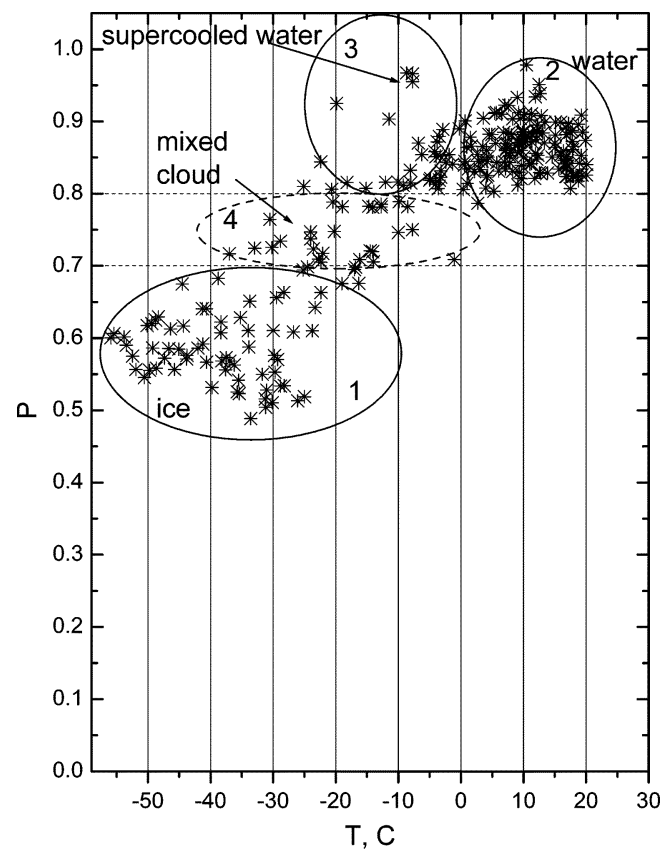

Fig. 2. P-T diagram. The temperature $T$ is expressed in degrees Celsius (see text) using brightness temperature measured by AATSR assuming that cloud can be represented as a black body. The phase index $\mathrm{P}$ is defined as the ratio of the reflectance at $1550 \mathrm{~nm}$ to that at $1670 \mathrm{~nm}$.

the threshold value $R_{c}=0.2$. Indeed, Kokhanovsky and von Hoyningen-Huene [6] showed that the reflection function over ocean is smaller than the nominal value $R_{c}$.

\section{P-T DIAGRAM}

A browse image of the scene analyzed from the orbit 08094 (17.09.2003, 14:50-15:03 UTC) of Envisat is shown in Fig. 1. It displays a portion of Hurricane Isabel close to the coast of Florida. The scatter diagram of phase index-temperature for the whole area is shown in Fig. 2. Only cloudy pixels with cloud coverage above $99 \%$ were selected for this study. The phase index $P$ is defined as the ratio of the reflection function at $1550 \mathrm{~nm}$ to that at $1670 \mathrm{~nm}$. Generally, the atmospheric extinction decreases with the wavelength. This leads to smaller atmospheric optical thickness and also smaller reflection function for larger wavelengths. Therefore, one may expect that $P$ is larger than one for cloudless atmosphere over ocean. The value of $P$ is smaller than one for clouds due to enhanced light absorption by liquid water or ice at $1550 \mathrm{~nm}$ as compared to that at the wavelength $\lambda=1670 \mathrm{~nm}$. An interesting point is that the value of $P$ is systematically smaller for ice as compared to liquid water. Knap et al. [5], Acarreta et al. [1], and Kokhanovsky et al. [7] have proposed to use this feature to identify ice clouds.

The spectral dependencies of the imaginary parts $\chi$ of the refractive indexes of water and ice in the interval $1300-1800 \mathrm{~nm}$ are presented in Fig. 3. It follows that the gradients of functions $\chi(\lambda)$ are larger for ice as compared to water in the spectral range $1500-1800 \mathrm{~nm}$. This also influences the spectral reflectance curves and, therefore, $P$. We have performed radiative transfer calculations of $P$ in the assumption that both cloud droplets and crystals have the spherical shape. The cloud optical thickness was varied in the range 5-30. The effective radii

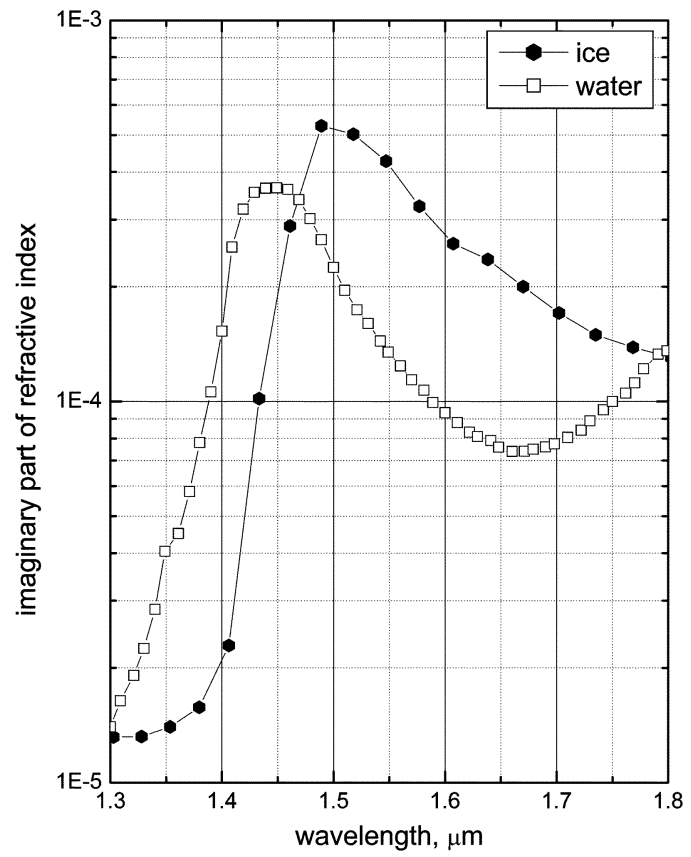

Fig. 3. Imaginary part of the complex refractive index of water [11] and ice [13].

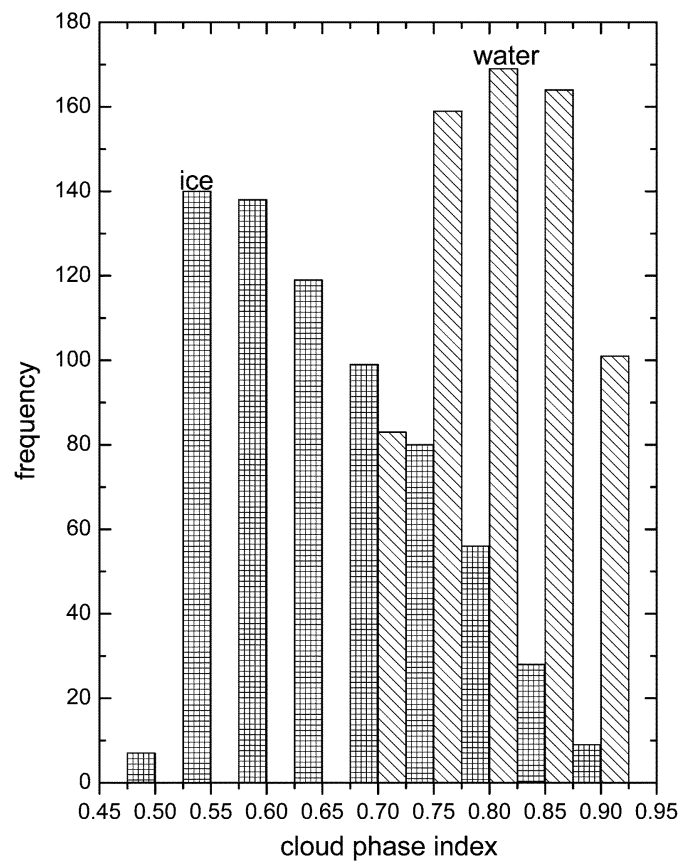

Fig. 4. Histogram of the cloud phase index.

of droplets and crystals were changed in the range 5-30 $\mu \mathrm{m}$. The frequency distributions of obtained values of $P$ for water and ice clouds are shown in Fig. 4. It follows that histograms of the phase index are different for ice as compared to water. The account for the nonspherical shape and the larger size of ice particles as compared to water droplets enhances these differences even further. We find that $P$ is in the range of [0.5-0.7] for most of ice cloud cases. Interestingly, our calculations are confirmed by Fig. 2 as well since it is known that water droplets do not exist at temperatures below $-40{ }^{\circ} \mathrm{C}$.

The detection of clouds with supercooled water is difficult with the concept of the phase index standing alone. On the 
other hand, mixed clouds can hardly be discriminated only using the brightness temperature $t$. The cloud-top temperature $T$ in degrees Celsius as shown in Fig. 2 is equal to $t-273.15$, where $t$ is obtained from measured brightness temperature (at $12 \mu \mathrm{m}$ ) assuming that the cloud can be modeled as a black body. Therefore, our technique is not suitable for semitransparent ice (cirrus) clouds where the surface temperature would affect the determination of $\mathrm{T}$ in the P-T diagram.

It is often observed, from in situ measurements [4], that the top of mixed-phase clouds is characterized by remnant supercooled water droplets whereas the rest of the cloud below is ice precipitating. This means that the radiative properties (measured from space) may be governed by water droplets rather than by ice crystals in these cases, hampering therefore the water-phase retrievals in lower cloud layers. In any case, the results given here are related to conditions at cloud tops. The technique is not capable to resolve vertical variations of the cloud phase.

The $P$ - $T$ diagram shown in Fig. 2 allows us to classify clouds with respect to their phase. It follows from Fig. 2 that the phase index is always larger than 0.8 for warm water clouds $(T>$ $\left.0{ }^{\circ} \mathrm{C}\right)$. It is in the range of [0.5-0.7] for cold ice clouds $(T<$ $-40{ }^{\circ} \mathrm{C}$ ). Usually, clouds with negative temperatures ranging from zero to $-40{ }^{\circ} \mathrm{C}$ are difficult to classify. However, taking threshold values 0.7 and 0.8 established above, we can identify liquid and solid water as shown in Fig. 2 even in this problematic region (the remaining data corresponding to mixed-phase clouds). In particular, four separate areas on the diagram shown in Fig. 2 can be distinguished.

- Region 1: Predominantly ice crystals are present. We see that pure crystalline clouds do not exist at temperatures above $-20{ }^{\circ} \mathrm{C}$ for the case studied. Indeed, for $T>-20^{\circ} \mathrm{C}$, the values of $P$ become larger than 0.7 thus indicating the presence of liquid water droplets. Moreover, particle size retrievals show that crystals at lower temperatures have generally smaller sizes as compared to the case of ice clouds at higher temperatures. This is demonstrated in Fig. 5, where the frequency distribution of the particle absorption length $\ell$ defined by Kokhanovsky and Nauss [8] is presented for the region 1 at temperatures below and above $-40^{\circ} \mathrm{C}$. The value of $\ell$ is proportional to the size of particles with the coefficient of proportionality dependent on assumed shapes of crystals as discussed in [8].

- Region 2: Warm Water Clouds. It follows from Fig. 2 that $P \geq 0.8$ for warm water clouds $\left(T>0{ }^{\circ} \mathrm{C}\right)$. Therefore, values of $P \geq 0.8$ at lower temperatures indicate supercooled water droplets.

- Region 3: Clouds With Supercooled Water Droplets. There are a lot of clouds with supercooled droplets in the temperature interval $\left[-20^{\circ} \mathrm{C}, 0^{\circ} \mathrm{C}\right]$ for the case studied. This coincides with aircraft observations performed in this range of cloud temperatures [10].

- Region 4: Mixed-Phase Clouds. This region is of a great importance for the formation of the precipitation. Interestingly, mixed clouds can exist in a wide range of temperatures down to $-40{ }^{\circ} \mathrm{C}$.

A technique solely based on the thermal IR measurements will identify clouds at $T>0{ }^{\circ} \mathrm{C}$ as liquid water clouds and

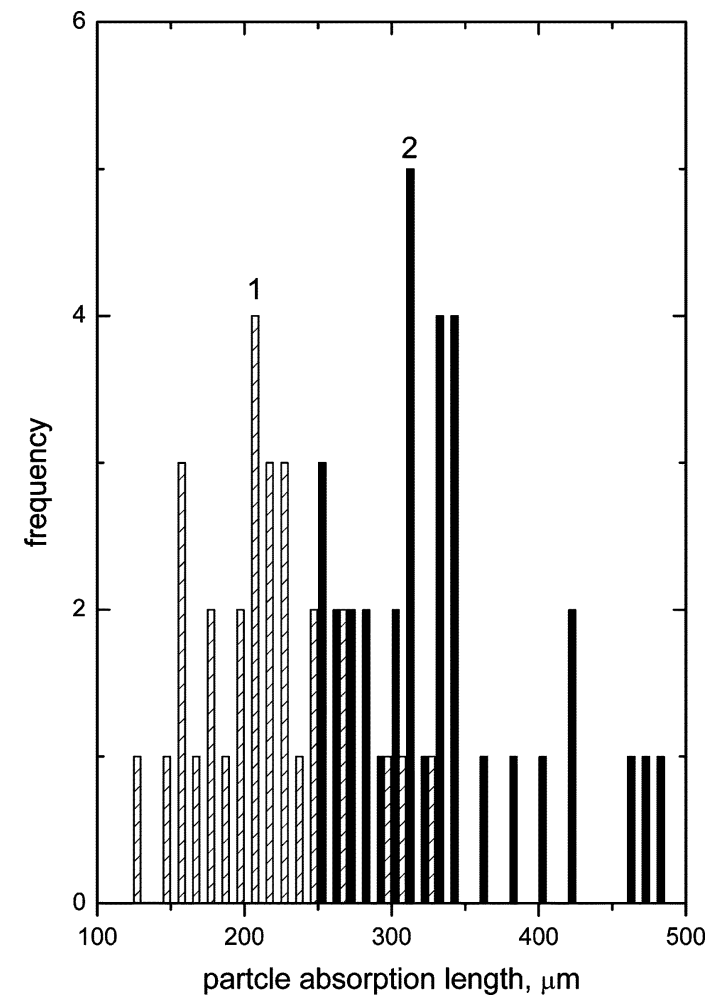

Fig. 5. Histogram of the particle absorption length as derived using a semianalytical cloud retrieval algorithm [8]. Black bars correspond to the region 1 at temperatures above $-40^{\circ} \mathrm{C}$. Light bars correspond to $T \leq-40^{\circ} \mathrm{C}$.

clouds with temperatures below $-40{ }^{\circ} \mathrm{C}$ as crystalline ones. Therefore, there is no way to assess the thermodynamic state in the region from $-40{ }^{\circ} \mathrm{C}$ until $0^{\circ} \mathrm{C}$ by the only use of thermal infrared measurements. However, we see that the concept of the phase index allows us to identify ice, supercooled water, warm water, and mixed clouds using the P-T diagram shown in Fig. 2. The concept of the phase index alone is not capable to distinguish regions with warm clouds and supercooled droplets (see Fig. 2). However, this is possible using the P-T diagram presented here.

The maps of temperature and thermodynamic phase for the case shown in Fig. 1 highly correlate (see Figs. 6 and 7). The state positioned in the vicinity of $30 \mathrm{~N}$ latitude (see Fig. 7) corresponds to the hurricane area as shown in browse image (see Fig. 1). We see that ice, mixed, and supercooled liquid water clouds are present in the area of a hurricane. Liquid water is mostly present close to the edge of the hurricane. Generally, the distribution of water with respect to its thermodynamic state is very complex in hurricanes and must be studied in more detail.

\section{ConClusion}

We propose a technique to identify various phases of water in clouds using near-IR and thermal IR measurements. On one hand, this shows the importance of synergy between various instruments on the same space platform (e.g., AATSR and SCIAMACHY on Envisat). On the other hand, this demonstrates the potential of adding one more channel $(1.55 \mu \mathrm{m})$ to the set of wavelengths available on AATSR $(0.55,0.67,0.87,1.6,3.7$, 10.7 , and $12.0 \mu \mathrm{m})$ for the cloud research. 


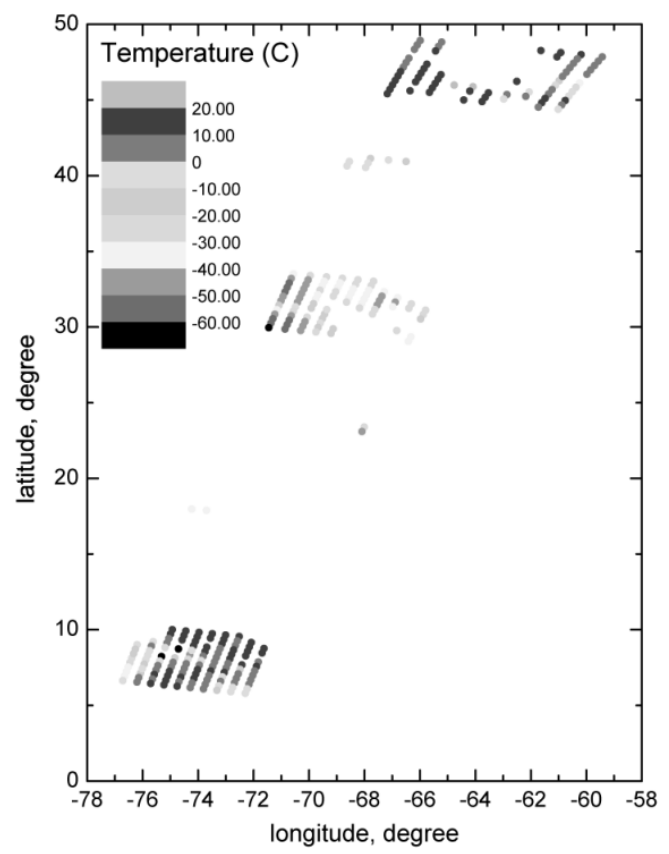

Fig. 6. Cloud-top temperature map for the area given in Fig. 1. Only results for $30 \times 60 \mathrm{~km}^{2}$ SCIAMACHY pixels with a cloud cover above $99 \%$ are shown. Pixels in the upper part of this figure correspond to clouds seen in the upper part of Fig. 1. Pixels around latitude $30 \mathrm{~N}$ correspond to the hurricane area shown in Fig. 1.

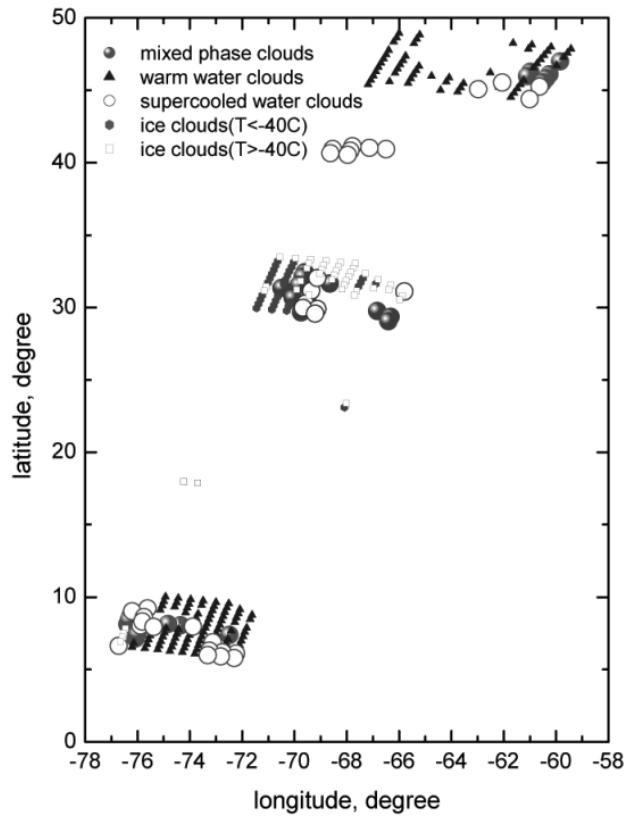

Fig. 7. Same as in Fig. 4 but for the cloud thermodynamic phase.

The advantage of the P-T diagram technique lies in the fact that it does not require complex numerical calculations. Also the method is very fast and simple. It can be put as the basis for the the automatic cloud TS determination numerical proce- dure using the analysis of the P-T thresholds as explained above. Clearly, independent measurements are needed to validate the performance of our technique.

It is of advantage to develop an instrumentation, which is capable to measure radiation at wavelengths $1.55,1.67$, and $12 \mu \mathrm{m}$ simultaneously and with a high spatial resolution. This will allow in the future to prepare maps as shown in Fig. 7 in a great more spatial detail and also better understand the cloud phase distribution in clouds and hurricanes. The task of this letter was to demonstrate the capability of the technique with the current state-of-the-art instrumentation. The technique can be used as a way to get an additional cloud product from the synergy of AATSR and SCIAMACHY.

\section{ACKNOWLEDGMENT}

The authors would like to thank the European Space Agency for providing satellite data.

\section{REFERENCES}

[1] J. R. Acarreta, P. Stammes, and W. H. Knap, "First retrieval of cloud phase from SCIAMACHY spectra around $1.6 \mu \mathrm{m}$," Atmos. Res., vol. 72, pp. 89-105, 2004.

[2] B. A. Baum, P. F. Soulen, K. I. Strabala, M. D. King, S. A. Ackerman, W. P. Menzel, and P. Yang, "Remote sensing of cloud properties using MODIS airborne simulator imagery during SUCCESS 2. Cloud thermodynamic phase," J. Geophys. Res., vol. 105, pp. 11781-11 792, 2000.

[3] H. Bovensmann, J. P. Burrows, M. Buchwitz, J. Frerick, S. Noël, V. V. Rozanov, K. V. Chance, and A. P. H. Goede, "SCIAMACHY: Mission objectives and measurement modes," J. Atmos. Sci., vol. 52, pp. 127-149, 1999.

[4] J. F. Gayet, S. Asano, A. Yamakzaki, A. Uchiyama, A. Sinyuk, O. Jourdan, and F. Auriol, "Two case studies of winter continental-type water and mixed-phase stratocumuli over the sea. Part 1: Microphysical and optical properties," J Geophys. Res., vol. 107, no. D21, pp. 4569-4570, 2002. DOI: 10.1029/2001JD001 106.

[5] W. H. Knap, P. Stammes, and R. B. A. Koelemeijer, "Cloud thermodynamic-phase determination from near-infrared spectra of reflected sunlight," J. Atmos. Sci., vol. 59, pp. 83-96, 2002.

[6] A. A. Kokhanovsky and W. von Hoyningen-Huene, "Optical properties of a hurricane," Atmos. Res., vol. 69, pp. 165-183, 2004.

[7] A. A. Kokhanovsky, V. V. Rozanov, T. Nauss, C. Reudenbach, J. S. Daniel, H. L. Miller, and J. P. Burrows, "The semianalytical cloud retrieval algorithm for SCIAMACHY. I. The validation," Atmos. Chem., Phys. Discussions, pp. 1995-2015, 2005.

[8] A. A. Kokhanovsky and T. Nauss, "Satellite-based retrieval of ice cloud properties using a semi-analytical cloud retrieval algorithm," J. Geophys. Res. D, 2005. DOI: 2004JD005744.

[9] P. Pilewskie and S. Twomey, "Discrimination of ice from water in clouds by optical remote sensing," Atmos. Res., vol. 21, pp. 113-122, 1987.

[10] H. R. Pruppacher and J. D. Klett, Microphysics of Clouds and Precipitation. Dordrecht, The Netherlands: Reidel, 1978.

[11] D. Segelstein, "The complex refractive index of water," M.Sci. thesis, Univ. Missouri, Kansas City, 1981.

[12] D. D. Turner, S. A. Ackerman, B. A. Baum, H. E. Revercomb, and P. Yang, "Cloud phase determination using ground-based AERI observations at SHEBA," J. Appl. Meteorol., vol. 42, pp. 701-715, 2003.

[13] S. G. Warren, "Optical constants of ice from the ultraviolet to the microwave," Appl. Opt., vol. 23, pp. 1206-1225, 1984. 